\title{
Annotation
}

\section{Diagnosis of malignant hyperphenylalaninaemia}

The occurrence of progressive cerebral degeneration in some patients with phenylketonuria (PKU) despite early and adequate dietary control of serum phenylalanine is now well established. The clinical syndrome was clearly described by Smith et al. ${ }^{1}$ At a conference held in Lausanne, June $1977,{ }^{2}$ of groups of people who have written papers on the subject, it was agreed that malignant hyperphenylalaninaemia (MHPA) was the best term to describe such cases. Readers seeking additional documentation of the facts should refer to the report of that meeting. ${ }^{3}$

MHPA is present in between 1 and $3 \%$ of babies with positive results to Guthrie tests, including some babies with serum phenylalanine levels lower than would customarily be treated with diet. ${ }^{4}$ All cases so far recognised suffer a deficiency of tetrahydrobiopterin $\left(\mathrm{BH}_{4}\right)$, the cofactor of phenylalanine hydroxylase, tyrosine hydroxylase, and tryptophan hydroxylase. Deficient production of the neurotransmitter products of tyrosine and tryptophan is regarded as the cause of the neurological effects ${ }^{5}$ and the gratifying results reported in Lausanne of treatment with L-dopa and 5-hydroxytryptophan support this contention. ${ }^{6}$ Two classes of basic defect have been found: deficiency of dihydropteridine reductase (DHPR) which is required for recycling $\mathrm{BH}_{4}{ }^{7}$ and defective synthesis of biopterin. ${ }^{7,8,9}$ Paediatricians treating PKU are faced with the need to identify patients with MHPA in order to treat them effectively and also to allow confident dietary treatment for the remaining $97-99 \%$ of patients with PKU. Patients with MHPA can then be further classified by DHPR assay on cultured skin fibroblasts (or on liver biopsy), by phenylalanine hydroxylase assay (on liver biopsy), and in future by assay of specific enzymes concerned in $\mathrm{BH}_{4}$ synthesis.

The time has now come to introduce systematic testing of all babies with persistently raised levels of serum phenylalanine by measuring the response to a single oral dose of $\mathrm{BH}_{4}(2 \mathrm{mg} / \mathrm{kg})$. This test should be performed as part of the initial work before diet is begun, and the serum phenylalanine level should be measured before and 6 hours after the dose. ${ }^{4}$ MHPA is recognised by a fall of serum phenylalanine to normal levels; patients with classical PKU show no response.

The advantage of this method is that the result can be known immediately, before diet is started, and no other laboratory test is needed. Lack of pure $\mathrm{BH}_{4}$ is the one problem at present, but if there were a demand from several clinics it could soon be made available. Several research laboratories are already synthesising $\mathrm{BH}_{4}$ and the quantities needed are not great.

We showed the effect of intravenous $\mathrm{BH}_{4}$ in a patient who was initially thought to have partial DHPR deficiency, ${ }^{10}$ but was later found to have severe DHPR deficiency. ${ }^{4}$ Comparable response in patients with deficient $\mathrm{BH}_{4}$ synthesis was expected and has now been shown by Schaub et al. who also showed that oral administration was as effective as parenteral. ${ }^{9}$

Another useful approach to the recognition of MHPA is the study of urinary pteridines. The simplest method is to estimate dihydroxanthopterin $\left(\mathrm{XH}_{2}\right)$ in urine. DHPR deficiency causes excessive levels of $\mathrm{XH}_{2}$ in the urine. ${ }^{11}$ The levels overlap those found in patients with classical PKU before treatment, and clear distinction requires retesting after dietary control when levels are still high in DHPR deficiency but have fallen to normal in classical PKU. Urinary $\mathrm{XH}_{2}$ should be abnormally low in patients with defects of $\mathrm{BH}_{4}$ synthesis. One may expect to find some precursors of $\mathrm{BH}_{4}$ in the urine in these cases. Doubtless high performance liquid chromatography of urine may give a diagnostic profile in such cases, but findings in DHPR deficiency can overlap those in classical PKU (before treatment). These approaches to diagnosis necessitate setting up new laboratory methods and there are likely to be delays in diagnosis because response to dietary treatment may be critical in some cases. Some of the chemicals measured are unstable in urine (in serum) and careful treatment of samples is necessary.

For all these reasons we feel convinced that the $\mathrm{BH}_{4}$ load test will become established as the best method for identifying cases of MHPA promptly and efficiently. Many different approaches are then possible in evaluating these few patients with MHPA to reach a final diagnosis, but proof of the enzyme defect is likely to remain the final arbiter.

\section{References}

'Smith, I., Clayton, B. E., and Wolff, O. H. (1975). New variant of phenylketonuria with progressive neurological 
illness unresponsive to phenylalanine restriction. Lancet, 1, 1108-1111.

${ }^{2}$ Danks, D. M. (1978). Pteridines and phenylketonuria. Journal of Inherited Metabolic Diseases, 1, 47-48.

${ }^{3}$ Danks, D. M., Bartholomé, K., Clayton, B., Curtius, H., Gröbe, H., Kaufman, S., Leeming, R. J., Pfeilderer, W., Rembold, H., and Rey, F. (1978). Current status of malignant hyperphenylalaninaemia. Journal of Inherited Metabolic Diseases, 1, 49-54.

${ }^{4}$ Danks, D. M., Schlesinger, P., Firgaira, F., Cotton, R. G. H., Watson, B., Rembold, H., and Hennings, G. (1979). Malignant hyperphenylalaninemia-clinical features, biochemical findings, and experience with administration of biopterins. Pediatric Research, in press.

${ }^{5}$ Butler, I. J., Koslow, S. H., Krumholz, A., Holtzman, N. A., and Kaufman, S. (1978). A disorder of biogenic amines in dihydropteridine reductase deficiency. Annals of Neurology, 3, 224-230.

${ }^{6}$ Bartholomé, K., and Byrd, D. J. (1975). L-Dopa and 5hydroxytryptophan therapy in phenylketonuria with normal phenylalanine hydroxylase activity. Lancet, 2 , 1042-1043.

${ }^{7}$ Kaufman, S., Holtzman, N. A., Milstein, S., Butler, I. J., and Krumholz, A. (1975). Phenylketonuria due to a deficiency of dihydropteridine reductase. New England Journal of Medicine, 293, 785-790.

${ }^{8}$ Rey, F., Harpey, J. P., Leeming, R. J., Aicardi, J., and Rey, J. (1977). Les hyperphenylalaninemies avec activité normale de la phenylalaninehydroxylase. Archives françaises de pediatrie, 34, Supplement 2, 109-120.

${ }^{9}$ Schaub, J., Däumling, S., Curtius, H-Ch., Niederwieser, A., Bartholomé, K., Viscontini, M., Schircks, B., and Bieri, J. H. (1978). Tetrahydrobiopterin therapy of atypical phenylketonuria due to defective dihydrobiopterin biosynthesis. Archives of Disease in Childhood, 53, 674-676.

${ }^{10}$ Danks, D. M., Cotton, R. G. H., and Schlesinger, P. (1976). Variant forms of phenylketonuria. Lancet, 1, 1236-1237.

${ }^{11}$ Schlesinger, P., Watson, B., Cotton, R. G. H., and Danks, D. M. (1979). Urinary dihydroxanthopterin in the diagnosis of malignant hyperphenylalaninaemia and phenylketonuria. Clinica chimica acta, 92, 187-195.

D. M. Danks, R. G. H. Cotron, AND P. SCHLESINGER

Royal Children's Hospital Research Foundation, Parkville, Victoria, Australia 3052 